\title{
Cine emergente en Ecuador: Poder y corrupción
}

\author{
El Gobernador | José Carmona | 2015
}

\author{
Álvaro Pazmiño Tello* y Marcela Mora**
}

\author{
Universidad Tecnológica Equinoccial, Ecuador
}

Recibido: 10 de mayo 2017; aceptado: 6 de julio 2017

\begin{abstract}
Resumen
El presente trabajo reflexiona sobre el cine emergente en Ecuador, a través del análisis sociopolítico del largometraje nacional El Gobernador, estrenado en el año 2015 y producido durante 10 días. Éste narra la historia de un reo político y su escape de la cárcel, tratando temas comunes como el poder y la corrupción. Asimismo, se realiza un análisis de audiencia con los estudiantes de la Facultad de Comunicación, Artes y Humanidades de la Universidad Tecnológica Equinoccial, como trabajo práctico del curso de Cinematografía, para profundizar en los significados asociados al film desde su carácter emergente. El cine emergente surge como la solución de las formas limitadas de producción y de bajo presupuesto, realizado en tiempo récord, con conceptos identificables socialmente y dirigido a audiencias locales o regionales. Este cine se arraiga al desarrollo de los aspectos técnicos y a la apertura de caminos comerciales.
\end{abstract}

Palabras clave: cine emergente | cine ecuatoriano | producción | audiencia.

Emerging film in Ecuador

\begin{abstract}
The present work reflects on the emerging film in Ecuador, through a structural analysis of the national feature film "The Governer", premiered in the year 2015 and produced for 10 days. This narrates the story of a political prisoner and his escape, dealing with common themes such as power and corruption. Likewise, an audience analysis is performed with the students from the Faculty of Communication, Arts and Humanity of the University Tecnológica Equinoccial, as practical Cinematography course work to deepen the meaning associated to the film from its emergent character. Emerging film arises as a solution to the limited production forms and low Budget cost, done in record time, with socially identifiable concepts directed to a local or regional audience. This cinema is rooted in the development of technical aspects and the opening of commercial roads.
\end{abstract}

Keywords: emerging film | ecuadorian cinema | production | audience

"El cine nos da a ver el proceso de penetración del hombre en el mundo y el proceso inseparable de penetración del mundo en el hombre"

Morín, 2001

\section{Contexto}

El cine es por mucho una de las aristas del arte en cuya ejecución mayor es la inversión que se exhorta, tanto así que para un artista plástico es posible trabajar aisladamente con sus materiales, en contraste al panorama del labor de un cineasta que involucra un conjunto de habilidades dispersas y articuladas en un equipo de trabajo, dentro del cual se incluye el talento humano necesario para cumplir con las diversas tareas que conlleva una producción, los dispositivos técnicos apropiados que permitan obtener una calidad óptima de imagen y sonido, y, demás elementos adicionales, como transporte e insumos de logística importantes; estos ineluctablemente exigen un considerable egreso en función de la proyección del retorno. Sistemáticamente, dedicarse a la producción cinematográfica también demanda contar con una organización holística bien estructurada y la programación de las actividades en función de sus temporalidades de acuerdo con su caracterización particular, el grado de dificultad técnica y el sentido de simultaneidad, de tal

\footnotetext{
apazmino@ute.edu.ec

***moritamarcela91@gmail.com
} 
forma que se definan dinámicas y etapas enmarcadas en sub-clasificaciones que van de corto a largo plazo dependiendo del tipo de producción que se haya dispuesto.

No obstante, y como todo proceso, el cine ha sido el conjunto de mejoras continuas desde la época del apogeo de las artes visuales. Desde la proyección de la salida de obreros de una fábrica francesa en Lyon, la demolición de un muro, la llegada de un tren, y un barco saliendo del puerto en 1985 en espacio público de Paris a cargo de Auguste Marie Louis Nicolas Lumière y Louis Jean Lumière, tan solo un mes después de que el cinematógrafo fue patentado, la cinematografía no dejó de ser la pasión de muchos. Así, en el territorio sudamericano el cine mudo, producido entre el primer cuarto y la tercera década del siglo XX, tuvo su auge, principalmente, en Argentina, México y Brasil; empero no únicamente del cine silente, sino que fueron los contextos del nacimiento del nuevo cine (el cine sonoro) en los países del sur del continente. Pero, ¿a qué se debió tal distinción? ¿Qué determinó la concentración del arte con cámaras en estos países? Puede ser que, al radicarse el universo de la cinematografía en los territorios sureños de América, los productores europeos se acomodaron ineludiblemente en las ciudades que presentaron mayores índices de comercio y en aquellas que centralizaron el poder administrativo de los territorios y, en especial, las dinámicas sociales dialécticas que caracterizaban la polaridad tiempo-espacio, significando periodos cortos en contraposición con las amplias medidas de crecimiento de los 'centros urbanos' durante la época. Estos determinantes se constituyeron informalmente con fines de facilidad en el rodaje y en la interconexión vial de las centralidades con las áreas rurales que permitió la movilización en red hacia distintos escenarios o, incluso, escenografías.

A pesar de las debilidades en la documentación no técnica del cine que profundice la historia del desarrollo cinematográfico dentro de las fronteras ecuatorianas -tal vez, debido a que en los años cincuenta, como menciona John King, "...el cine ecuatoriano estaba dominado por las importaciones norteamericanas y mexicanas...” (King, 1994, p. 279)-, a diferencia de la producción endémica que desarrollaban los países aledaños en la época, es bien conocido en el mundo de las cámaras que el origen de la producción del cine sonoro comercial ecuatoriano fue el indigenismo como centro temático de la producción nacional en la época y, en específico con la estelar de la película Fuera de aquí, que trata de forma inteligible la inserción del imperialismo en el país. "De acuerdo con los investigadores de la Universidad de
Quito, que financió parcialmente el proyecto, la película fue vista por más de tres millones de personas (de una población global de ocho millones) y tuvo una amplísima cobertura a través de los circuitos alternativos en todo el país" (King, 1994, p. 275) ${ }^{1}$.

El carácter emergente del cine en el Ecuador puede ser catalogado como una etapa en la línea de tiempo de la historia de la cinematografía nacional; no obstante del claro contexto, cabe la necesidad de profundizar en el significado y su repercusión en el mercado del cine, considerando que uno de los objetivos de la producción de películas, además del desarrollo de los aspectos netamente técnicos, es ampliar el camino comercial en virtud de los productos generados gracias al conjunto de esfuerzos y capitales invertidos en su creación.

\section{Situación actual de cine en Ecuador}

No muy alejado del indigenismo, el Estado ecuatoriano ha establecido un régimen de incentivos y ha destinado inversión para mantener un Fondo de Fomento Cinematográfico, en reconocimiento de la industria del cine nacional, con la finalidad de estimular las actividades dedicadas a este tipo de producciones en el país, en especial aquellas rodadas y procesadas en el Ecuador, cuya temática y objetivos tengan relación con expresiones culturales o históricas del país. La Ley de Fomento del Cine Nacional, publicada en Registro Oficial Nro. 202, de 3 de febrero de 2006, establece que para ser partícipes de dicho estímulo, la producción debe ser catalogada por el Consejo Nacional de Cinematografía como película nacional, y que las mismas que sean producidas por personas, empresas u organizaciones con domicilio legal en el Ecuador, cuyo director y al menos uno de los guionistas sean de nacionalidad ecuatoriana o extranjero residente en el Ecuador; así como que los equipos artísticos y técnicos integrados tengan el mismo origen.

Como apoyo a la industria del cine nacional, el Estado, por medio de las entidades estatales competentes, concederá créditos con tasas de interés y plazos preferenciales, destinados a la producción nacional de películas, documentales, obras artísticas y culturales para cine (LFCN, 2006, art. 4).

De acuerdo con el Ministerio de Cultura y Patrimonio del Ecuador, el 2011 fue el año con mayor número de espectadores de películas nacionales en salas de cine comercial con 335.595 , que representa el $83,90 \%$; mientras que hacia el año 2015 la concurrencia disminuyó 17,08\%, 
legando a 68.305 espectadores (MCyP, n.d.). Esta cúspide estadística del año 2011 probablemente esté relacionada con el estreno de la obra cinematográfica ecuatoriana taquillera $A$ tus espaldas, de Tito Jara, en abril.

Sin embargo, el mayor número de obras cinematográficas independientes de producción y coproducción nacional se ubican entre los años 2013 (36 películas) y 2015 (35 películas); además en proporción al número de obras cinematográficas independientes de producción y coproducción nacional que han sido estrenadas en el transcurso de un año en salas de cine comercial, la cifra más alta se ubica en el año 2014 con una diferencia de 2 puntos en relación al 2013 y de 5 con respecto al 2015; siendo en el 2013, 16; en el 2014, 18; y en el 2015, 13.

El significante fílmico (en las connotaciones) no es nunca una imagen sino una relación...de esta manera el mundo duplicado en la imagen se presenta como algo que existe realmente, pero que a través de su conjunto de relaciones determinadas y determinantes (Santos, 2003, pág. 179).

\section{El término cine emergente}

El término cine, a finales del siglo XVIII, carecía de existencia en el bagaje de vocabulario de la época; no obstante ya se mencionaba un glosario conexo, tal como la cinemática, en relación al movimiento que proviene de la voz griega kinématikos (Echegaray, 1887, p. 246).

Creado a finales del siglo XIX, cine proviene a partir de dos palabras griegas: kıvń (kiné), que quiere decir movimiento, y de үрафós (grafós) que significa imagen. De ahí que se define al cine, en su sentido más básico, como imagen en movimiento.

Conceptualmente, se puede definir al cine como "la forma vívida de registrar la realidad, de plasmar en imágenes y sonidos la historia y de testimoniar desde un simple acontecimientos hasta toda una concepción política, ideológica y filosófica sobre la realidad" (Cineteca Nacional de México, 1974, pág. 8).

Por su lado, la normativa ecuatoriana define a la obra cinematográfica de la siguiente manera:

Es el registro organizado de tomas o imágenes asociadas con o sin sonorización incorporada que, independientemente de las características del soporte material que la contiene y de su duración, está destinado esencialmente a ser mostrada a través de aparatos de proyección o destinada a ser proyectadas prioritariamente en salas de cine. Se entenderá por largometraje aquellas cuya du- ración sea mayor a 60 minutos y cortometraje las que duren menos de 60 minutos (LFCN, 2006, art. 10).

Según Burch la narrativa fílmica, tiene su origen en tres aspectos: en primer lugar, las tradiciones populares que se han influenciado del melodrama en las representaciones artísticas populares en ferias, parques, canciones tradicionales; tradiciones arraigadas en un sincretismo cultural que ha mezclado el pensamiento occidental y las tradiciones indígenas. El segundo aspecto se centra en la ciencia aplicada y todo avance tecnológico referido a la captación de la imagen en movimiento. Y el tercer aspecto está influenciado por las formas burguesas de representación del arte como la literatura y el teatro. Estos factores se han conjugado para crear la narrativa fílmica en las películas de la región y, en particular, en el caso ecuatoriano (Burch, 1987).

Por su lado, y ya que el fin es nombrar al cine que se desarrolla con recursos, en general, limitados como emergente es menester buscar la raíz del término para mantener una base conceptual sobre lo que después definiremos como cine emergente. Precisamente, emergente viene del latín emergere que se entiende como aparecer o elevarse, compuesto de ex en referencia hacia el exterior y el verbo mergere que significa hundimiento. De tal forma que, como adjetivo, se conceptualiza como el que nace, sale y tiene principio de otra cosa (DLE, 2016).

Entonces, el cine emergente puede definirse como el registro sistemático de imágenes en movimiento audiovisuales, a ser proyectadas hacia audiencias locales o regionales que recurre a emplear formas de producción limitada; realizado de manera modesta y con tópicos diversos identificables socialmente. Esta forma particular de producción hace posible merecer rodajes en tiempo record. En este conjunto se puede citar el caso de la película ecuatoriana El Gobernador. El director José Carmona puede dar luces sobre el criterio del cine emergente en esta producción:

Algo importante que quiero compartir, y es los procesos que nos ayudaron, es decir la estructura que nos ayudó para poder lograr nuestro rodaje en 10 días es de alguna $u$ otra forma una buenacopia que queremos traernos y plasmarla aquí en E cuador. Realmente lo que nosotros queremos hacer y nos es un secreto aquí voy a compartirlo, nosotros tenemos una excelente etapa de pre producción nosotros tenemos 3 meses trabajos sobre una mesa, en la que tenemos el libreto en frente y analizamos escena por escena decantamos las posibles escenas de riesgo o los posibles costos adicionales que pueda tener la película (Carmona, 2015). 
En cuanto a la localización de la película, el apoyo de los entes gubernamentales fue limitado como comenta el productor Carlos Castro:

Sí. Trabajamos en dos locaciones, la primera en una cárcel que la acondicionamos en este sentido nos tocó a hacer a nosotros la cárcel directamente porque pedimos ayuda a los entes del estado, existían tres cárceles que estaban libres sin nadie que era el penal García Moreno la cárcel 4 y otra cárcel más, se nos hizo hacer todo el trámite burocrático, retrasamos dos meses la película y al final no se nos podía dar.

Fue un proceso que lo queríamos hacer, nos íbamos a detener por nada, hicimos nuestra propia cárcel y la segunda locación la hicimos en la mitad del mundo ahí es donde acondicionamos para poder hacer nuestra película (Castro, 2015).

La realidad de esta producción ecuatoriana, así como de gran parte de las producciones nacionales, radica en el empleo de recursos limitados para llevar a cabo sus producciones. Cada realizador resuelve sus dificultades de un modo específico. En el caso del film El Gobernador se realizaron reuniones de trabajo intensivas para trabajar la pre-producción, que duró aproximadamente tres meses.

\section{El caso: El Gobernador}

Se detallan a continuación los datos generales de la película:

Se produjo en Ecuador, en el año 2015, por Cinetel. Director: José Carmona; Productor General: Carlos Castro Nieto; Productora Ejecutiva: María Cristina Salinas; Guion Original: Juan Manuel Rodríguez; Dirección de Arte: Rosa María Tudela, Sebastián Terán, José Medina; Maquillaje: Gabriela Celi; y Vestuario: Daniela Mariño.

Para comenzar con el análisis del film, se ha rescatado la sinopsis oficial que brinda una idea del argumento:

El Gobernador es una película ecuatoriana de acción, que trata sobre las circunstancias extremas que experimenta al interior de una cárcel un político acusado por un delito de malversación de fondos públicos, Esteban Jara, protagonista interpretado por el reconocido actor de origen cubano Félix Antequera. El largometraje fue rodado en la ciudad de Quito, durante 10 días, entre el 12 y el 22 de febrero de 2015.

Con el fin de estudiar el film en sus etapas de desarro- llo del libreto se desglosará la estructura en: a) inicio de la historia, b) planteamiento del conflicto, c) desarrollo del conflicto y d) final de la historia.

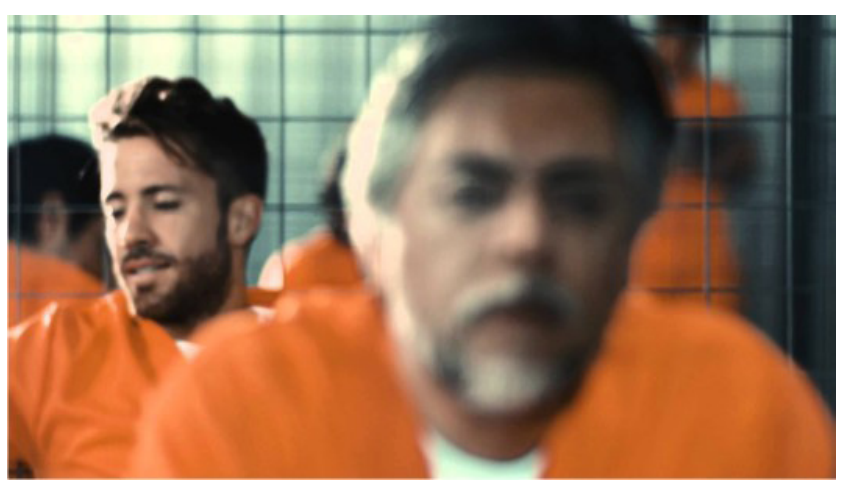

\section{a) Inicio de la historia}

A una cárcel de presos políticos llega un delincuente común: El Alfil, enviado por un grupo de mafiosos para sacar información al Gobernador (Esteban Jara).

Jara, durante un juego de ajedrez con su mejor amigo Miguel se percata de la presencia del recién llegado.

El Gobernador, quien jamás había compartido su celda, se ve obligado a hacerlo con el recién llegado, su compañero de celda, El Alfil, quien toma el control y hace hincapié que a partir de ese momento todo cambiará, intimidando a Jara. Durante el desayuno, este último se queja de la irrupción en su celda; sin embargo, desde entonces es tratado como un preso regular.

\section{b) Planteamiento del conflicto}

El capitán Benítez, jefe de los policías de la cárcel, se entrevista con la directora del recinto: Silvana Carmona.

Las intenciones de Alfil son claras: obtener información a Jara sobre los supuestos millones que se robó en su mandato, a cualquier costa.

En una reunión de presos en el patio del centro penitenciario Silvana se aproxima a realizar una ronda y el Gobernador expresa su malestar frente al maltrato recibido de Benítez y del nuevo recluso, pero solo consigue que le ratifique el carácter común del trato para el preso antes privilegiado.

Ya en su oficina, Silvana Carmona recibe una llamada, una voz presiona por conocer la ubicación de los millones que Jara mantiene en secreto. 


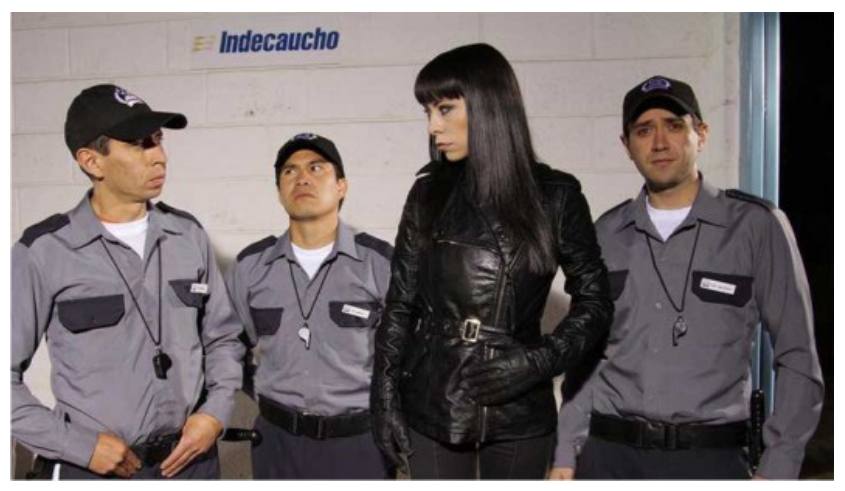

\section{c) Desarrollo del conflicto}

Inician las acciones de presión sobre el Gobernador, El Alfil estruja verbal y físicamente a Jara para lograr una confesión, sin lograr que confiese. La directora de la cárcel confronta a Jara en un intento para que revele el escondite de los millones robados.

En respuesta a su resistencia, como parte de la escalada de la tortura, El Alfil amedrenta a Jara de manera brutal, le propina una serie de golpes para lograr su confesión. Sin obtener resultados, la directora vuelve a intentar presionar verbalmente a Esteban. Miguel, su leal amigo, llega a la celda del gobernador para ver su estado.

En vista de la falta de respuestas por parte del recluso Gobernador, la directora, recurre a otro método y convoca a la amante de Esteban; La joven entra a la celda y se retira sin conseguir ninguna declaración.

Sin mayor antecedente, el Gobernador imparte lecciones de ajedrez a El Alfil, quien, con gran concentración, presta atención a la explicación del juego, las reglas básicas y como se mueve cada pieza en el tablero. A Esteban expresa su asombro frente al desconocimiento de ajedrez por parte de El Alfil, considerando la casualidad de su sobrenombre. Por su lado, Al Alfil le parece más curioso que su jefe tenga cierta fascinación por este juego y haya decidido ponerle a cada uno de sus trabajadores, el nombre de una ficha de ajedrez. El recluso recién llegado, se compara con un peón, en lugar que con el que hace alusión a su apodo.

Carmona se ausenta de las instalaciones de la cárcel presionada por una llamada telefónica. En medio de una de sus rondas de vigilancia, Benítez se acerca a la celda compartida por el Gobernador y El Alfil; quien bajo fuerza es invitado a sentarse con ellos para poner en práctica un plan de escape esa misma noche, a cambio de 10 millones de dólares.
La directora informa a Benítez de su apresurado retorno, por lo que la huida se adelanta y Miguel se une a la comitiva. Ya en la ejecución del plan, Esteban hace una parada en la oficina de Silvana para recuperar un documento importante. Luego de recorrer los corredores de escape del centro carcelario, los reclusos logran escapar en la camioneta del capitán Benítez, hacia una localidad no definida.

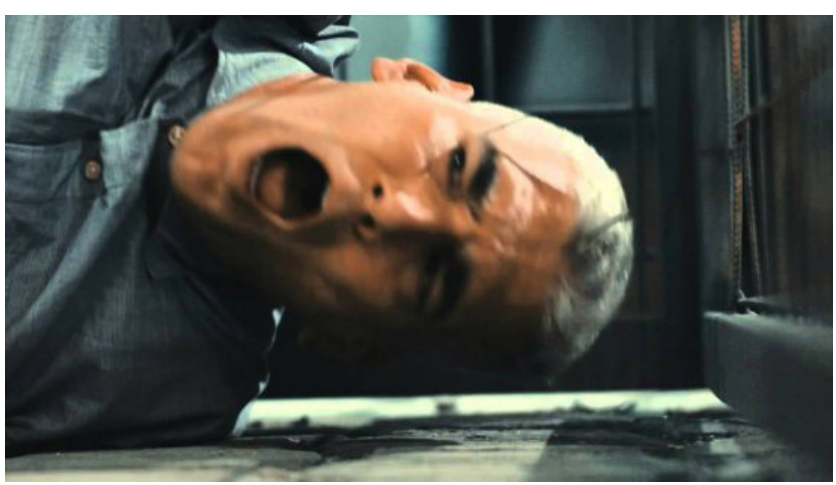

\section{d) Final de la bistoria}

El Alfil dispara a Benítez, cuyo cuerpo abandonan en el camino. Esteban en demostración de confianza, entrega los datos de la ubicación de los millones robados.

Mientras los hombres que han presionado por la información están persiguiendo a los prófugos, en la cárcel torturan y asesinan a Mendieta, último hombre en el caso de corrupción. El Alfil, dispuesto a matar al Gobernador una vez que le entregue las claves bancarias, es herido de muerte, lo que permitió la huida de Jara y Miquel. No obstante, solo un recluso logra huir: Miguel, quien ha matado a El Gobernador y escapa con toda la información, junto con la amante de Esteba Jara.

\section{Análisis de audiencia}

Para conocer la aceptación y reacciones sobre el film se realizó un grupo focal con estudiantes de la facultad de Comunicación, Artes y Humanidades de la Universidad Tecnológica Equinoccial Quito. Así, las impresiones de los participantes del grupo que, en su mayoría, están acostumbrados al cine comercial, especialmente hollywoodense, se centran en críticas positivas sobre el uso y aplicación de planos de cámara, y en la capacidad de producción en relación al limitado tiempo de rodaje; aspectos que se enmarcan en el cine emergente de la 
región. En cuanto a la historia, el punto de atención se concentró en la planeación del escape y en los acuerdos que se llevaron a cabo para su ejecución. Se mencionó que la película mantenía un grado de aceptabilidad en todos sus aspectos, incluso que la historia es intrigante. Respecto de la temática, se determinó que el giro de la historia contó con un quiebre sobre la perspectiva de los buenos y malos de la historia entre el inicio y el final, lo que le otorgó un toque de realismo al filme.

Las tensiones percibidas están relacionadas con la ejecución del rodaje, sobre todo los efectos, el concepto de la historia, los guiones, el sonido, el manejo de diálogos y una post-producción mal lograda. Una de las críticas respecto de los actores fue que, en su mayoría, no son ecuatorianos, por lo que, a pesar de que la producción es nacional, se cuestiona su carácter nacional, considerando que existen profesionales nacionales en actuación que pudieron haber aportado y logrado un ahorro en la producción.

Del total de participantes, el 12,5\% acepta como positivos todos los aspectos técnicos y conceptuales de la película El Gobernador; el 50\% considera que el film tiene aspectos positivos y que otros pudieron haberse logrado de mejor manera; y el 25\% emitió críticas sobre los aspectos negativos de la producción.

\section{Análisis Socio-político}

El film de ficción $E l$ Gobernador es estelarizado en un contexto que pretende reflejar una posible realidad política, mediante la historia de un caso de corrupción y de timas políticas y económicas, cuestiones que se relacionan pragmáticamente con varios escenarios que, en distintos desenlaces, conservan la esencia del concepto del guión de la producción; sobre todo, considerando los escenarios que normalmente se ignoran, como la realidad al interior de los centros de reclusión que son poco documentados, y que los relatos sobre las peripecias de las personas privadas de la libertad definen perfiles diversos de la vida de los presos que incluyen redes de corrupción en su interior, redes que, incluso sobrepasan la ilusión de poder de quienes administran las cárceles, así como los intereses ilícitos de las figuras de vigilancia que rondan los pasillos de estos establecimientos.

La película pretende describir intromisiones conocidas que en el contexto de algunos países se han nombrado -como en Ecuador el caso del Notario Cabrera-, e intenta contar una historia desde la otra perspectiva, aquella que ningún documental considera en su guión, es decir, distinta a la del Estado y de sus instituciones, de los bancos y sus operaciones contables, como se realizó con A tus espaldas, constituyendo una de las causas de su éxito. Así, socialmente, relatar una ficción desde la configuración de un recluso puede traer sugestivos aportes que muestran realidades escuchadas, pero no documentadas.

No obstante, producciones de este tinte y con este esquema documental requieren de realidades que socialmente no generen especulación, sino que cuenten la historia de hechos formalmente comprobados.

\section{Conclusiones}

La cinta El Gobernador, es un producto dirigido a toda la región ya que topa temas comunes como la corrupción y el manejo carcelario. La incorporación de actores de varias nacionalidades potencia al producto para ser distribuido a otros países; lo que, nacionalmente, puede ser cuestionable al no encontrar el dialecto del país sede de la producción. Yendo más allá, para los mercados iberoamericanos dichos acentos se desdibujan ya que se corre el riesgo de distorsionar la percepción del resto de los posibles espectadores sobre los acentos ecuatorianos. Por tal motivo, este aspecto podría ser superable para el espectador, siempre que la historia sea ampliamente compartida en el imaginario de los cinéfilos.

En definitiva, el nulo apoyo de los entes rectores del cine en el país, motivó la aplicación de un plan de producción con tiempos apretados y recursos propios que devinieron en una producción de bajo presupuesto que cuenta una historia de interés, como es la corrupción.

\section{Referencias}

Burch, N. (1987). El Tragaluz del infinito: contribución a la geneaología del lenguaje cinematográfico. Madrid: Cátedra.

Carmona, J. (2015). Película El Gobernador. (Cinetel, Entrevistador)

Castro, C. (2015). Película El Gobernador. (F. Cine, Entrevistador)

Cineteca Nacional de México. (1974). México: Sistema del Banco Nacional Cinematográfico. 
DLE. (2016). Diccionario de la Lengua Española. Recuperado el 28 de septiembre de 2016, de http://dle.rae.es

Echegaray, D. E. (1887). Diccionario General Etimológico de la Lengua Española. Madrid: José María Faquineto.

Jara, T. (Director). (2011). A tus espaldas [Motion Picture]. Ecuador.

King, J. (1994). El Carrete Mágico: Una historia del cine latinoamericano (Primera edición ed.). Colombia: Tercer Mundo Editores.

LFCN. (2006). Ley de Fomento del Cine Nacional. Quito: Registro Oficial 202, 3 de febrero de 2006.

MCyP. (n.d.). Ministerio de Cultura y Patrimonio. Retrieved 20162 йил 13-octubre from http://picultural.culturaypatrimonio.gob. ec/

Morín, E. (2001). El cine o el hombre imaginario. Barcelona: Paidós.

Santos, Z. (2003). Pensar la imagen. Madrid: Cátedra.

1 Información proporcionada por el autor, referenciada en el libro de King. 